\title{
New insights into the appendage morphology of the Cambrian trilobite-like arthropod Naraoia compacta
}

\author{
CAROLIN HAUG \& JOACHIM TOBIAS HAUG
}

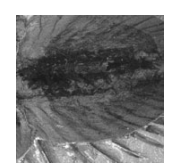

\begin{abstract}
For understanding the life habits of extinct organisms, functional morphology is of crucial importance. In arthropods, the morphology of the appendages in particular gives insights into the mode of life. Yet, in the fossil record of arthropods mainly dorsal structures are preserved, as they are often more sclerotised or even mineralised. Exceptions are, for example, the species of Naraoia from the Cambrian Burgess Shale (about 508 million years old), of which the appendages are also preserved. We present here new details of the appendages of Naraoia compacta, which were made visible with modern imaging methods that were not yet available during former investigations. According to our re-study, the appendage shows a division into basipod, endopod and exopod. The basipod-body joint has not been visible to earlier investigators, and both basipod and endopod are significantly more strongly adorned than previously interpreted. The most important difference to earlier studies regards our interpretation of the exopod morphology. According to our new data, the exopod is composed of a series of similar, small paddles attached to a shaft, and not feather-like in appearance. This morphology has a strong impact on the swimming behaviour of $N$. compacta, as the paddles can be closed to form a functionally single large paddle during the power stroke, and will be opened during the recovery stroke to reduce the water drag. In this way, our new data provide important insights into the life habits of this long extinct species. $\bullet$ Key words: Burgess Shale, Naraoia, trilobites, gills, exopod, functional morphology.
\end{abstract}

HAUG, C. \& HAUG, J.T. 2016. New insights into the appendage morphology of the Cambrian trilobite-like arthropod Naraoia compacta. Bulletin of Geosciences 91(2), 221-227 (2 figures, online appendix). Czech Geological Survey, Prague. ISSN 1214-1119. Manuscript received June 20, 2015; accepted in revised form February 12, 2016; published online April 18, 2016; issued June 30, 2016.

Carolin Haug \& Joachim Tobias Haug (corresponding author), LMU Munich, Department of Biology II and GeoBio-Center, Großhaderner Str. 2, 82152 Planegg-Martinsried, Germany; carolin.haug@palaeo-evo-devo.info

Arthropods (in the strict sense) are characterised by their jointed appendages (e.g. Boxshall 2004, Maas et al. 2004). For understanding the evolutionary success of this group and also their internal relationships, understanding their appendages is of high significance (e.g. Hou \& Bergström 1997; Waloszek et al. 2005, 2007).

This also holds true for fossil arthropods. Quite commonly in the fossil record only dorsal, often mineralised cuticle details of arthropods are available, yet it is their ventral details, especially the appendages, which can often bring the most surprising insights.

At the evolutionary level of Euarthropoda the appendages are what is commonly called biramous: a basipod, a rigid proximal element with median armature involved in feeding, carries two distal rami, an inner branch often thought to be involved in walking, composed of more or less tubular elements (endopod) and an outer branch which is plesiomorphically paddle-shaped (exopod) and often equipped with numerous setae along its outer margin (e.g.
Hou \& Bergström 1997; Maas et al. 2004; Waloszek et al. 2005, 2007; Haug et al. 2013a).

Many modern arthropods, such as many chelicerates and insects, appear to lack the exopod (e.g. Wolff \& Scholtz 2008, Haug et al. 2013a), but for example fossil chelicerates demonstrate that early representatives originally had outer branches, exopods (Sutton et al. 2002, Haug et al. 2012a, b). The identity of some of these supposed fossil exopods has been questioned (Wolff \& Scholtz 2008), yet, the structural and positional similarities of some of these structures to the exopods of for example early representatives of Crustacea (sensu lato) makes homology of these structures likely (cf. Stein et al. 2008, Haug et al. 2010, Haug et al. 2012b).

The exopod has been often termed "gill branch" in the past (e.g. Whittington 1977). Yet, there is growing evidence that these structures were not involved in respiration (Suzuki \& Bergström 2008, Suzuki et al. 2008, Maas et al. 2009). To be more precise, exopods do increase the body 
surface-to-volume ratio and thus could well have had a positive effect on passive gas exchange, but for demonstrating a true respiratory nature one would need to demonstrate the presence of thin plated epithelia, which would allow active oxygen transport. This could only be founded on the basis of ultra-structural details, which are unlikely to be detected in a fossil. Comparison to preserved definite respiratory structures, unequivocal gills, shows little resemblance (e.g. Martins-Neto 1996, Schram \& Dixon 2004, Poschmann et al. 2008); exopods and their sub-structures appear significantly more rigid. More likely the exopods were used in active swimming, at least in some species (Stein et al. 2008, Haug et al. 2012b).

Thus, exopod morphology can tell us some aspects of the functional morphology and autecology of a species, e.g. swimming capabilities. Even more, specific exopod morphologies can also tell about the relationship of an arthropod. Specialised morphologies can be used for characterising monophyletic groups. Examples are 1) representatives of Crustacea sensu lato, which possess multi-annulated exopods with relatively few annuli and exclusively median setation on appendages two and three (e.g. Waloszek et al. 2007, Stein et al. 2008, Haug et al. 2010) and 2) marrellomorphs which are characterised by multi-annulated exopods with numerous annuli equipped with flattened lamellae on all trunk appendages (Kühl et al. 2008, Kühl \& Rust 2010, Haug et al. 2013b).

Another specialised exopod morphology is known from trilobites, of which few species have become known from their appendages (e.g. Raymond 1920, Bergström 1969, Whittington \& Almond 1987, Ramsköld \& Edgecombe 1996, Hou et al. 2008). In fact two types of exopod morphologies in trilobites can be differentiated. One type is only known from Ceraurus pleurexantemus. Here the exopod is composed of five elements, the distal one being paddle-shaped and equipped with strong spine-like setae (Størmer 1939). The other type could be described as distantly resembling a feather, a central shaft bears many thin lamellae, and often there is additionally a distal setose paddle (e.g. Whittington 1975, 1980).

A similar morphology of the exopod has been found in different species of Naraoia Walcott, 1912 (Whittington 1977, Chen et al. 1997, Hou \& Bergström 1997), a reason why these were often considered to be a kind of soft trilobites (e.g. Whittington 1977). Newer phylogenetic analyses resolved a more distant relationship between naraoiids and trilobites, yet these analyses are heavily based on details of the dorsal morphology rather than on aspects of the ventral details such as appendages (e.g. Paterson et al. 2010 and references therein).

We report new details and a new interpretation of the appendage morphology of Naraoia compacta Walcott, 1912 from the Cambrian Burgess Shale KonservatLagerstätte. These fossils have become famous for their exquisite preservation of finest details. These new interpretations are discussed in the light of the evolution of exopod morphologies within euarthropods.

\section{Material and methods}

The investigated specimens of Naraoia compacta are part of the collection of the Smithsonian National Museum of Natural History, Washington, D.C. (USNM), which were also the basis for the investigations of Whittington (1977) and Zhang et al. (2007). The specimens were documented dry under polarized light with a Canon EOS Rebel T3i camera with a MP-E 65mm macro lens and a Canon Macro Twin Lite MT-24EX flashlight. Polarised light enhances the contrast of the fossil against the matrix significantly (Schaarschmidt 1973, Bengtson 2000) and especially highlights finest detail such as setae or spines (Haug et al. 2011, 2012a, b; Stein \& Selden 2012).

To overcome the limited field of view several images were taken of each specimen and stitched with Adobe Photoshop CS3 (Haug et al. 2012b). A 3D model of a generalised trunk appendage in Fig. 1D, E was reconstructed in open-source software Blender based on the photographs (Maas et al. 2007; Stein et al. 2008; Haug et al. 2010, 2011, 2012a, b; Stein \& Selden 2012).

\section{Results and discussion}

\section{Observed morphology and interpretation}

Many specimens of Naraoia compacta preserve details of the appendages (Fig. 1A, B). There are different appearing features in different fossils, which are attributed to preservational variation, mainly different planes of embedding (see Whittington 1977, his fig. 1 for examples for such variations). The observed structures are therefore interpreted in a way that could explain these different positions.

The appendage has three principal major parts, the proximal basipod which carries the two distal rami, the inner endopod and the outer exopod (Fig. 1C). The basipod is drawn out medially on its distal side, resulting in an oblique median edge (Fig. 1D). Distally on this edge there is one prominent spine, which is slightly downward curving (Fig. 1D). Smaller spines are arranged in two rows along the median edge, an anterior and a posterior row. Both rows have about 8-10 spines. A group of at least four medially pointing spines is present on the anterior surface, medio-distally. Three more spines are positioned medially, medio-distally from the prominent spine, closer to the insertion of the endopod (Fig. 1D).

The endopod comprises six elements (Fig. 1C). The proximal element is drawn out medially into one large 


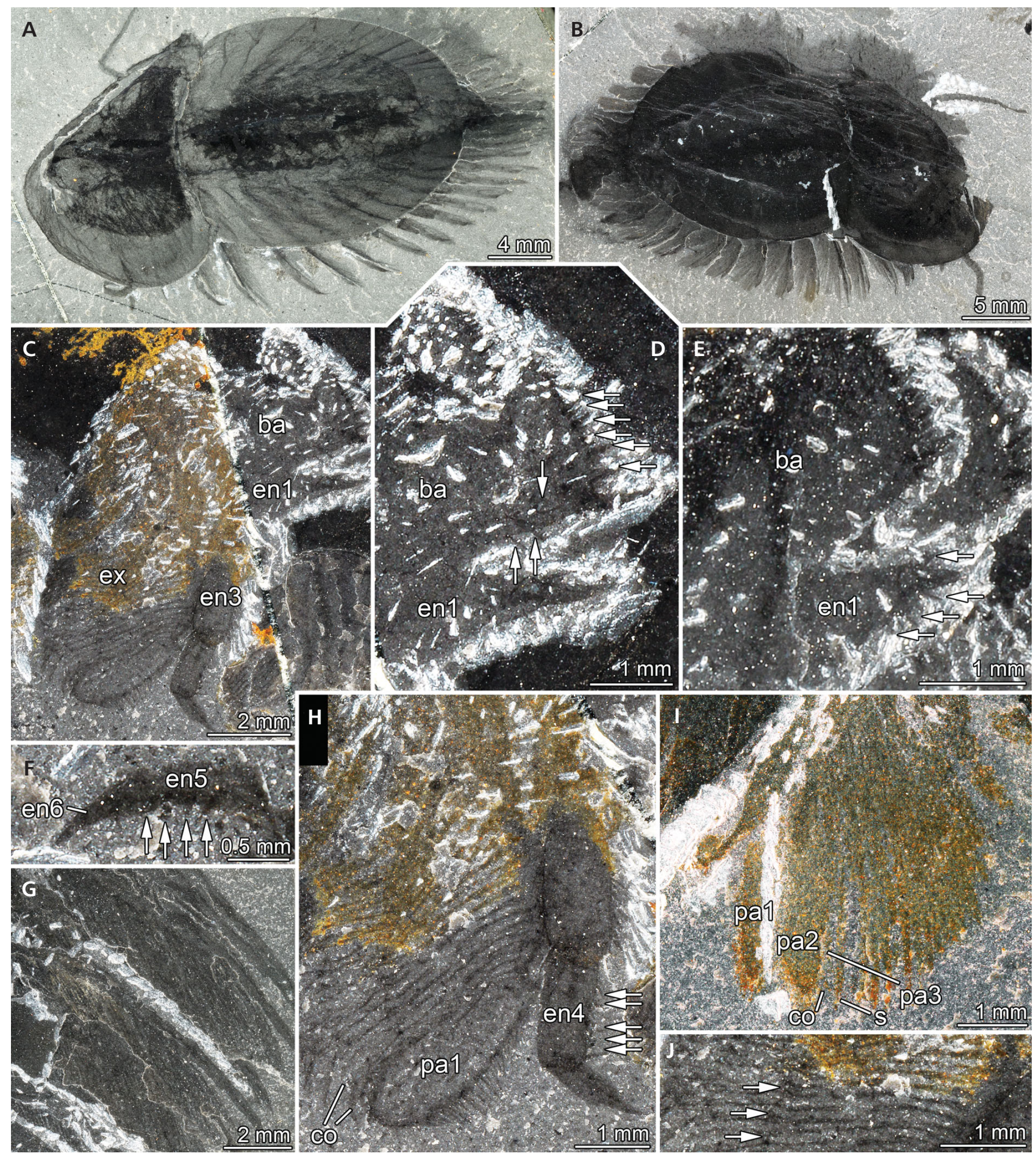

Figure 1. Specimens of Naraoia compacta. The white structures represent preparation marks. • A, B - dorsal view of complete specimens, appendages, mainly exopods, protruding from under the head and trunk shields. $\bullet^{\bullet}$ - well-preserved trunk appendage with basipod (ba), exopod (ex) and endopod (en). $\bullet \mathrm{D}$ - close up on the median edge of the basipod. Arrows mark spines. $\bullet \mathrm{E}-$ close up on endopod element one. Arrows mark spines. $\bullet \mathrm{F}-$ close up on distal part of the endopod. Arrows mark spines. $\bullet \mathrm{G}$ - exopods preserved in "feathery" appearance. $\bullet \mathrm{H}$ - close up on exopod and endopod shown in $\mathrm{C}$. Note the distal paddle (pa1) and the similar curving outlines (co) of the supposed filaments, i.e. the outlines of underlying paddles. Arrows mark spines on the endopod. $\bullet$ I - displaced distal paddle (pa1) reveals another paddle below (pa2) and a not so well-preserved third paddle (pa3) with its curved outline (co) and a single preserved seta (s). $\bullet \mathrm{J}$ - close up of H. Setules marked by arrow on supposed filaments. A - USNM 57868; B - USNM 83945B; C, D, F, H, J - USNM 199815; E - USNM 189221; G - 189216; I - USNM 189222. 
spine (Fig. 1D). This spine is armed with spinules closer to the tip (Fig. 1E). The next four elements are more tubular in shape and equipped with small spines along their median edge (Fig. 1C, F, H). The distal element is a small spine-like, slightly inward curved claw (Fig. 1F).

The exopod is more difficult to interpret, as it can be preserved in different aspects. Its central part, the shaft, can usually be well recognised (Fig. 1G). In some specimens the distal end carries a paddle that is equipped with numerous small setae (Fig. 1H). Yet, in many specimens this distal paddle cannot be observed (Fig. 1G). We interpret this apparent absence as a result of a different angle of view of this distal paddle. In specimens where the paddle appears to be absent we only see its edge, not the face ( $c f$. Whittington 1977).

Proximal to the distal paddle up to 20 structures are present (Fig. 1H), which are usually described as filaments, i.e. long thin, but flattened derivatives of setae ( $c f$. Whittington 1977, Haug et al. 2013b). Yet, we offer an alternative interpretation for these structures.

In specimens where the distal paddle and the exopod are preserved and appear undistorted we can observe that the supposed filaments follow exactly the outline of the distal paddle, including the distal curving towards the tip of the paddle (Fig. 1H). We interpret this in the following way: the supposed filament is nothing more than the outline of another paddle lying below the distal paddle. In further consequence all supposed filaments are interpreted as outlines of paddles, the distal paddle representing the uppermost one of a stack. That mainly the outline of these paddles is preserved and not the face can also be seen in the preserved distal paddles (Fig. $1 \mathrm{H}$ ). This interpretation is supported by specimens in which the distal paddle is displaced. Here it becomes obvious that the supposed filament proximal to the paddle is more areal than a thin filament and indeed also represents a paddle (Fig. 1I). Furthermore, under high magnification small setae can be identified in the supposed filaments, with this resembling the armature of the distal paddle (Fig. 1J).

The shaft is thus interpreted as not bearing two types of structures, many thin filaments and a setose distal paddle, but only one type of structures, a series of setose paddles (Fig. 2A). This interpretation explains the uniformity of the structures along the shaft in the two major types of preservation: In specimens with undistorted visible paddles the supposed filaments are distally curving, while all filaments appear to be straight, especially distally in the cases where the distal paddle appears to be absent (Fig. 1G). In the first case the distally rounded edge of the stacked paddles can be seen from their anterior, but mainly concealed faces (thus appearing to be curved, Fig. 2A), while in the other case only the edges, but not their faces, which are turned away from the viewer, can be seen appearing to be more straight (Fig. 2B). These two ways of preservation also indicate that the paddles were attached in an oblique angle to the shaft (Fig. 2A, B, online supplementary file). Such an oblique attachment of supposed filaments to the shaft was also reconstructed for Chinese Naraoia species (Hou \& Bergström 1997).

Following Ockham's razor we see that the given explanation requires fewer assumptions: one type of structure with always the same shape, but seen from two different angles. The alternative explanation instead demands having two types of structures of which the first one (distal paddle) sometimes cannot be differentiated, but sometimes can, and the second one (filaments) is sometimes straight whereas in other cases it is curved, but just at the very distal end.

\section{Comparison with Whittington's interpretations}

The reconstruction presented here differs from that presented by Whittington (1977) in several aspects. As stated before the same material that was the basis for this study was already used by Whittington (1977). He also used the same specimens as we did for understanding the appendages (e.g. USNM 199815, which according to Whittington has the best preserved appendages).

There are two main reasons for differing interpretations: 1) New methods. Polarised light has offered many new minute details of various Burgess Shale arthropods, which simply appear to be not visible under normal light conditions. 2) New interpretations on close relatives. Whittington (1977) stated that, for example, the "coxa"-body joint (basipod-body joint) is not observable in the fossils. Therefore, he must have based his reconstruction on available data from other supposedly closely related arthropods, especially trilobites. Yet, the interpretation of trilobite appendage orientation has been questioned in recent years (e.g. Stein \& Westheide 2007), a typical wide stance with arched endopods as supposed not only for trilobites but also for other Cambrian arthropods such as Burgessia bella (Hughes 1975) is now substituted by a more "hanging down" position of the appendages (e.g. Hou \& Bergström 1997). All well-preserved appendages of Naraoia compacta are also in concordance with such a position.

Besides a new supposed orientation of the basipod body joint, the main new find on basipod and endopod is that they are significantly better adorned than thought before. This is a simple effect of the application of polarised light.

Our exopod interpretation differs more fundamentally from that of Whittington (1977). Whittington, as we did, considered different planes of embedding and came to the result that the distal paddle (terminal lobe in his terminology) can be seen or not, depending on the embedding (his fig. $1 \mathrm{~A}, \mathrm{~B})$. He did not observe the distal curvature of the 


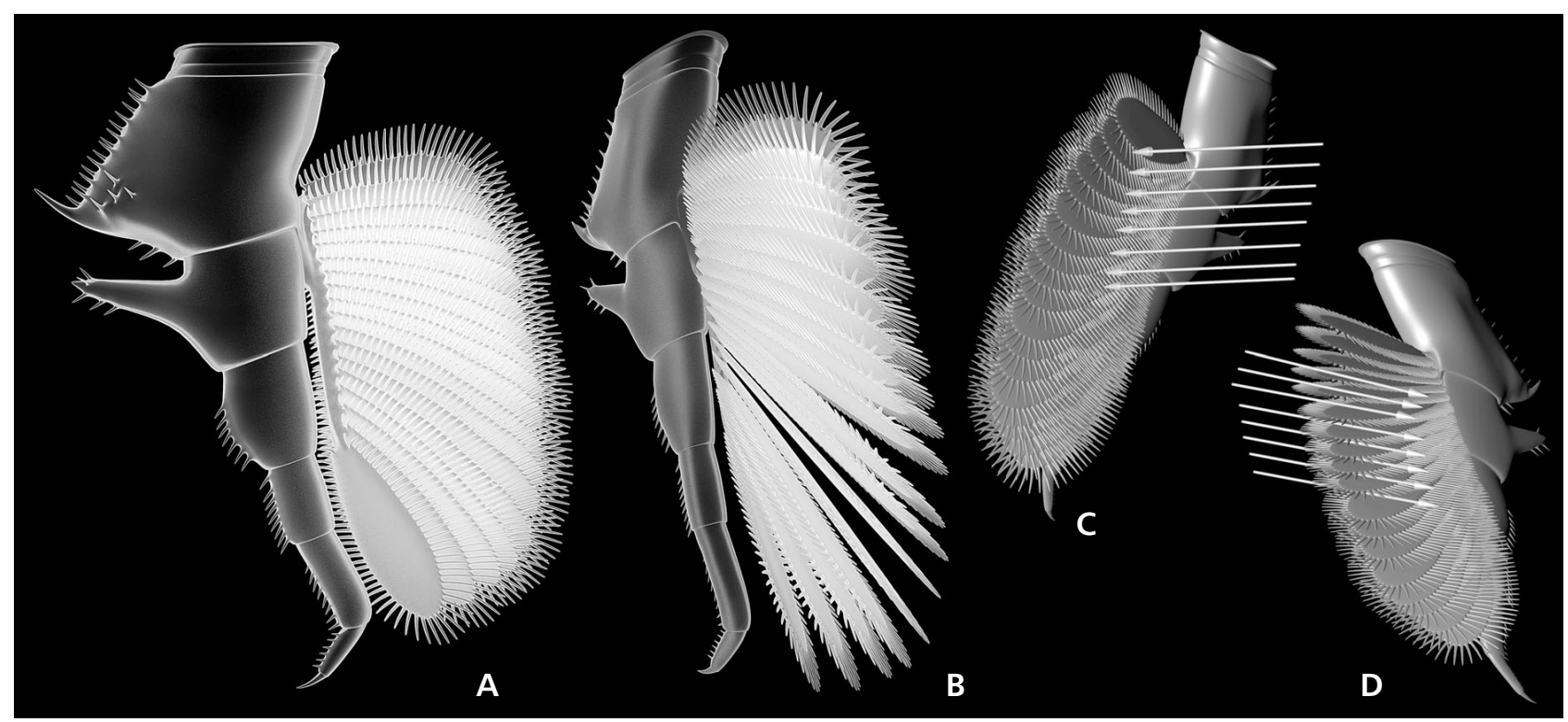

Figure 2. 3D models of a trunk appendage of Naraoia compacta. $\bullet \mathrm{A}, \mathrm{B}$ - examples of different appearances of the paddles in different embeddings. - A - anterior view. The most distal paddle is visible as such; further proximal paddles are mainly seen from their distally curving edges. $\bullet$ B - oblique view. Most of the paddles are only visible as straight edges; the distal paddle is not visible as such. $\bullet$ C, D - functional interpretation. View from slightly posterior during metachronal beat. $\bullet \mathrm{C}$ - beginning of the power stroke. The force of the water (arrows) would press the paddles against each other forming a functionally single large paddle. $\bullet$ D - beginning of the recovery stroke. The force of the water (drag) would be reduced as water could partly pass through the gaps between the paddles (arrows), passively forcing the paddles apart and stabilising them in this position.

supposed filaments when the face of the distal paddle was visible, and reconstructed them as straight (his fig. 1E). Whittington (1977) suggested that the supposed lamellae should be relatively stiff, but this is not in concordance with such a distal curvature. It is therefore most likely that he could not observe this detail; it might have been not accessible without polarised light. We conclude that Whittington's interpretations were plausible given the knowledge and technology of the time, but are not compatible with our new finds.

\section{Functional interpretation}

For the newly interpreted appendage morphology of Naraoia compacta functional aspects should also be discussed. Whittington (1977) interpreted $N$. compacta as a benthic predator walking on the sea floor, with the exopods being folded more or less backwards, "sandwiched" between the far dorsally arched endopods and the tergopleural area of the trunk (Whittington 1977, his fig. 96). The different orientation presented here, with the appendages more hanging down, leaves significantly more space for the exopods, making it likely that these could be well incorporated into locomotion.

During a supposed metachronal beat, the series of small paddles could form a large single functional paddle during the power stroke of a swimming motion. Due to their supposed oblique orientation at the beginning of the power stroke, the force of the water could have even slightly passively rotated the small paddles partly closing the gaps between them to make the functional single paddle more effective (Fig. 2C). Due to their supposed position, at the beginning of the recovery stroke the paddles could have passively rotated into the other direction and let water pass between them, with this reducing the drag force significantly (Fig. 2D). The appendages of Naraoia compacta appear thus to have been well adapted for effective swimming.

The general softness of Naraoia compacta (Fig. 1A, B) furthermore hints to a relatively low density of the body, which should have provided buoyancy. In addition to the flatness of the body, which occurs also in different extant nectic and planktic arthropods (e.g., fish lice, phyllosoma and other crustacean larvae; see Martin et al. 2014 for a recent overview), these factors are indicative for a necto-benthic instead of a benthic life habit of $N$. compacta. The well equipped basipods and endopods would thus have been less involved in walking, but more in feeding.

\section{Phylogenetic implications}

Based on published literature it is not possible do judge whether other fossil species with supposed filaments on their exopods also bear a series of paddles instead (e.g. Hou $\&$ Bergström 1997). It would not be surprising to find differences among the supposed closely related species now 
attributed to a monophyletic group Naraoia. Published images of Naraoia longicaudata, for example, give indeed the impression of a feathery exopod (Hou \& Bergström 1997, their fig. 41). Dorsal morphology appears to be highly likely to be homoplastic. This could be especially true for a group that is in fact characterised by an extremely simplified dorsal morphology such as Naraoia, i.e. the main character identifying Naraoia is rather information-poor. More complex, especially ventral characters should allow a more reliable evaluation of relationships. Yet, this will require a future re-investigation or at least re-evaluation of the appendages of the different arthropod species of interest, free of any pre-assumptions concerning their morphology. The principal interpretation of other trilobite-type exopods could be correct and $N$. compacta could represent a special case. Yet, it is also possible that at least some fossil arthropods with supposed "feathery" exopods indeed also bear a series of paddles instead.

Serially arranged small setose paddles on the exopod occur also in several other Cambrian arthropods, among them Emeraldella brocki (Burgess Shale) (Stein \& Selden 2012), Retifacies abnormalis and Kuamaia lata (both Chengjiang fauna) (Hou \& Bergström 1997). Naraoia compacta appendages might thus not be so special at all; this distinct appendage morphology, serially arranged paddles on the exopod, could characterise a large group of Cambrian arthropods.

It will not only be necessary to re-investigate species of Naraoia, but many more of the Cambrian fossils for this aspect. In recent years the interpretation of Cambrian arthropods, especially of their appendage morphologies had to be corrected (Stein \& Selden 2012; García-Bellido \& Collins 2006, 2007; Haug et al. 2011, 2012a, b). Many of them proved to be less different from the generally expected morphology than previously assumed (e.g. Haug et al. 2011). The here presented morphology of $N$. compacta could be considered as representing another such example of an earlier misinterpretation.

\section{Acknowledgments}

The presented study was only possible with the help of many people and organisations. G.D. Edgecombe, London, and J.-P. Lin, Taipei, gave helpful comments on the manuscript. D.H. Erwin, M.S. Florence and K.A. Hollis, Smithsonian National Museum of Natural History, Washington, D.C. (USNM), kindly provided access to the specimens. The authors were supported by D.E.G. Briggs, Yale University and Yale Peabody Museum of Natural History. CH was supported by the German Academic Exchange Service (DAAD) with a return fellowship. JTH was funded by Yale University and by the Alexander von Humboldt-Foundation with a Feodor Lynen research fellowship for postdoctoral researchers and a Feodor Lynen return fellowship. We would like to thank the programmers of the freeware Blender.

\section{Supplementary file}

Rotating 3D model of trunk appendage of Naraoia compacta (http://www.geology.cz/bulletin/supplement/1573_ Haug_supplementary_material.mp4).

\section{References}

Bengtson, S. 2000. Teasing fossils out of shales with cameras and computers. Palaeontologia Electronica 3(4), 14 pp.

Bergström, J. 1969. Remarks on the appendages of trilobites. Lethaia 2, 395-414.

DOI 10.1111/j.1502-3931.1969.tb01259.x

Boxshall, G.A. 2004. The evolution of arthropod limbs. Biological Reviews 79, 253-300. DOI 10.1017/S1464793103006274

Chen, J.-Y., Edgecombe, G.D. \& RAmsköLd, L. 1997. Morphological and ecological disparity in naraoiids (Arthropoda) from the Early Cambrian Chengjiang Fauna, China. Records of the Australian Museum 49, 1-24. DOI 10.3853/j.0067-1975.49.1997.249

García-Bellido, D.C. \& Collins, D.H. 2006. A new study of Marrella splendens (Arthropoda, Marrellomorpha) from the Middle Cambrian Burgess Shale, British Columbia, Canada. Canadian Journal of Earth Sciences 43, 721-742. DOI 10.1139/e06-012

García-Bellido, D.C. \& Collins, D.H. 2007. Reassessment of the genus Leanchoilia (Arthropoda, Arachnomorpha) from the Middle Cambrian Burgess Shale, British Columbia, Canada. Palaeontology 50, 693-709. DOI 10.1111/j.1475-4983.2007.00649.x

Haug, J.T., Briggs, D.E.G. \& Haug, C. 2012b. Morphology and function in the Cambrian Burgess Shale megacheiran arthropod Leanchoilia superlata and the application of a descriptive matrix. BMC Evolutionary Biology 12, art. 162.

DOI 10.1186/1471-2148-12-162

Haug, J.T., Castellani, C., Haug, C., Waloszek, D. \& Maas, A. 2013b. A Marrella-like arthropod from the Cambrian of Australia: A new link between "Orsten"-type and Burgess Shale assemblages. Acta Palaeontologica Polonica 58, 629-639.

Haug, J.T., Maas, A., Haug, C. \& Waloszek, D. 2011. Sarotrocercus oblitus - small arthropod with great impact on the understanding of arthropod evolution? Bulletin of Geosciences $86,725-736$. DOI 10.3140/bull.geosci.1283

Haug, J.T., MaAs, A., Haug, C. \& Waloszek, D. 2013a. Chapter 2. Evolution of Crustacean Appendages, 34-73. In WATLING, L. \& Thiel, M. (eds) Vol. 1. Functional Morphology and Diversity of the Crustacea. The Natural History of The Crustacea. Oxford University Press, Oxford.

Haug, J.T., MaAs, A. \& WaloszeK, D. 2010. †Henningsmoenicaris scutula, $†$ Sandtorpia vestrogothiensis gen. et sp. nov. and heterochronic events in early crustacean evolution. Earth and Environmental Science Transactions of the Royal Society of Edinburgh 100, 311-350. DOI 10.1017/S1755691010008145

Haug, J.T., Waloszek, D., MaAs, A., Liu, Y. \& Haug, C. 2012a. Functional morphology, ontogeny and evolution of mantis 
shrimp-like predators in the Cambrian. Palaeontology 55, 369-399. DOI 10.1111/j.1475-4983.2011.01124.x

Hou, X. \& Bergström, J. 1997. Arthropods of the Lower Cambrian Chengjiang Fauna, Southwest China. Fossils and Strata $45,1-116$

Hou, X., Clarkson, E.N.K., Yang, J., Zhang, X., Wu, G. \& YuAn, Z. 2008. Appendages of early Cambrian Eoredlichia (Trilobita) from the Chengjiang biota, Yunnan, China. Earth and Environmental Science Transactions of the Royal Society of Edinburgh 99, 213-223.

DOI 10.1017/S1755691009008093

Hughes, C.P. 1975. Redescription of Burgessia bella from the Middle Cambrian Burgess Shale, British Columbia, Canada. Fossils and Strata 4, 415-433.

KÜHL, G., Bergström, J. \& RUST, J. 2008. Morphology, palaeobiology and phylogenetic position of Vachonisia rogeri (Arthropoda) from the Lower Devonian Hunsrück Slate (Germany). Palaeontographica A 286, 123-157.

KüHL, G. \& Rust, J. 2010. Re-investigation of Mimetaster hexagonalis: A marrellomorph arthropod from the Lower Devonian Hunsrück Slate (Germany). Paläontologische Zeitschrift 84, 397-411. DOI 10.1007/s12542-009-0049-x

Maas, A., Haug, C., Haug, J.T., Olesen, J., Zhang, X. \& WALOSZEK, D. 2009. Early crustacean evolution and the appearance of epipodites and gills. Arthropod Systematics and Phylogeny 67, 255-273.

Maas, A., Waloszek, D., Chen, J., Braun, A., Wang, X. \& Huang, D. 2004. Phylogeny and life habits of early arthropods - predation in the early Cambrian sea. Progress in Natural Science 14, 158-166.

DOI 10.1080/10020070412331343301

Maas, A., Waloszek, D., Haug, J.T. \& Müller, K.J. 2007. A possible larval round worm from the Cambrian 'Orsten' and its bearing on the phylogeny of Cycloneuralia. Memoirs of the Association of Australasian Palaeontologists 34, 499-519.

Martin, J.W., Olesen, J. \& HøEG, J.T. 2014. Atlas of Crustacean Larvae. 384 pp. Johns Hopkins University Press, Baltimore.

Martins-Neto, R.G. 1996. New mayflies (Insecta, Ephemeroptera) from the Santana Formation (Lower Cretaceous), Araripe Basin, Northeastern Brazil. Revista Española de Paleontología 11, 177-192.

Paterson, J.R., Edgecombe, G.D., García-Bellido, D.C., Jago, J.B. \& Gehling, J.G. 2010. Nektaspid arthropods from the lower Cambrian Emu Bay Shale Lagerstätte, South Australia, with a reassessment of lamellipedian relationships. Palaeontology 53, 377-402. DOI 10.1111/j.1475-4983.2010.00932.x

Poschmann, M., Dunlop, J.A., Kamenz, C. \& Scholtz, G. 2008. The Lower Devonian scorpion Waeringoscorpio and the respiratory nature of its filamentous structures, with the description of a new species from the Westerwald area, Germany. Paläontologische Zeitschrift 82, 418-436.

RamsKöLD, L. \& Edgecombe, G.D. 1996. Trilobite appendage structure - Eoredlichia reconsidered. Alcheringa 20, 269-276.

RAYMOND, P.E. 1920. The appendages, anatomy, and relationships of trilobites. Memoirs of the Connecticut Academy of Sciences 7, 1-169.

SChaARschmidt, F. 1973. Pflanzenfossilien in ungewöhnlichem Licht. Natur und Museum 103, 247-253.

Schram, F.R. \& DixON, C.J. 2004. Decapod phylogeny: addition of fossil evidence to a robust morphological cladistic data set. Bulletin of the Mizunami Fossil Museum 31, 1-19.

Stein, M. \& Selden, P.A. 2012. A restudy of the Burgess Shale (Cambrian) arthropod Emeraldella brocki and reassessment of its affinities. Journal of Systematic Palaeontology 10, 361-383.

Stein, M., Waloszek, D., MaAs, A., Haug, J.T. \& Müller, K.J. 2008. Oelandocaris oelandica revisited. Acta Palaeontologica Polonica 53, 461-484.

Stein, M. \& Westheide, W. 2007. †Trilobita, Dreilapper, 474-477. In Westheide, W. \& Rieger, R. (eds) Spezielle Zoologie. Teil 1: Einzeller und wirbellose Tiere. $2^{\text {nd }}$ edition. Elsevier, Spektrum Akademischer Verlag, München.

STøRMER, L. 1939. Studies on trilobite morphology, Part I. The thoracic appendages and their phylogenetic significance. Norsk Geologisk Tidsskrift 19, 143-274.

Sutton, M.D., Briggs, D.E.G., Siveter, DA.J., Siveter, De.J. \& ORR, P.J. 2002. The arthropod Offacolus kingi (Chelicerata) from the Silurian of Herefordshire, England: computer based morphological reconstructions and phylogenetic affinities. Proceedings of the Royal Society of London B 269, 1195-1203.

SuZuKi, Y. \& BergströM, J. 2008. Respiration in trilobites: a reevaluation. GFF 130, 211-229.

DOI 10.1080/11035890809452774

Suzuki, Y., Kondo, A. \& Bergström, J. 2008. Morphological requirements in limulid and decapod gills: a case study in deducing the function of lamellipedian exopod lamellae. Acta Palaeontologica Polonica 53, 275-283.

DOI 10.4202/app.2008.0208

Waloszek, D., Chen, J.-Y., MaAs, A. \& Wang, X. 2005. Early Cambrian arthropods - new insights into arthropod head and structural evolution. Arthropod Structure and Development 34, 189-205. DOI 10.1016/j.asd.2005.01.005

Waloszek, D., MaAs, A., Chen, J.-Y. \& Stein, M. 2007. Evolution of cephalic feeding structures and the phylogeny of Arthropoda. Palaeogeography, Palaeoclimatology, Palaeoecology 254, 273-287. DOI 10.1016/j.palaeo.2007.03.027

Whittington, H.B. 1975. Trilobites with appendages from the Middle Cambrian Burgess Shale, British Columbia. Fossils and Strata 4, 97-136.

Whittington, H.B. 1977. The Middle Cambrian trilobite Naraoia, Burgess Shale, British Columbia. Philosophical Transactions of the Royal Society of London B 280, 400-443. DOI 10.1098/rstb.1977.0117

Whittington, H.B. 1980. Exoskeleton, moult stage, appendage morphology, and habits of the Middle Cambrian trilobite Olenoides serratus. Palaeontology 23, 171-204.

Whittington, H.B. \& Almond, J.E. 1987. Appendages and habits of the Upper Ordovician trilobite Triarthrus eatoni. Philosophical Transactions of the Royal Society of London B 317, 1-46. DOI 10.1098/rstb.1987.0046

Wolff, C. \& Scholtz, G. 2008. The clonal composition of biramous and uniramous arthropod limbs. Proceedings of the Royal Society of London B 275, 1023-1028.

DOI 10.1098/rspb.2007.1327

Zhang, X.L., Shu, D.-G. \& Erwin, D.H. 2007. Cambrian naraoiids (Arthropoda): morphology, ontogeny, systematics, and evolutionary relationships. Paleontological Society Memoir 68, 1-52. DOI 10.1666/06-082.1 